\title{
A PRELIMITARY STUDY OF THERAPEUTIC DOMAIN FOR BONE TUMOR USING ULTRASOUND HYPERTHERMIA
}

\author{
Bing-Yuh Lu' ${ }^{1}$, Rong-Sen Yang ${ }^{2}$, Win-Li Lin ${ }^{3}$, Kung-Shan Cheng ${ }^{3}$, Cheng-Yi Wang ${ }^{3}$, Te-Son Kuo ${ }^{1,3}$ \\ Departments of 'Electrical Engineering and ${ }^{2}$ Orthopaedics ${ }^{3}$ Center for Biomedical Engineering \\ National Taiwan University, Taipei, Taiwan, ROC \\ Email:d83048@me.ee.ntu.edu.tw
}

\begin{abstract}
This work applies a simplified model (a cone with convergent /divergent shape) to examine the optimal driving frequency, specific absorption ratio (SAR), and therapeutic domain for application of ultrasound hyperthermia to treat the bone tumor. The total ultrasound energy followed the exponential law for attenuation and uniform ideal power deposition within the cone-shape model. The relationship between the optimal driving frequency and correspondingly treated tumor size and depth was evaluated. To deliver the ultrasound energy into the tumor site and to avoid the potential damage to the normal tissue as much as possible, the ratio values of SAR distributions have to meet the criteria of SAR in bone tumor site being three times higher than the SARs in surface skin, bone marrow and bone. This criteria has been used to find the proper heating domain of ultrasound driving frequency and therapeutic tumor diameter in our model. The results demonstrated that the optimal driving frequency depends on the density ratio of bone to tumor, tumor depth, ultrasound absorption of bone marrow, and diameter of bone, whereas independent of the acoustic window area and SAR ratio. The temperature distributions can verify the SAR ratio criteria in this simplified model.

KEYWORDS: therapeutic domain, ultrasound hyperthermia, bone tumor, optimal driving frequency, bone tumor therapy, treatment planning
\end{abstract}

\section{INTRODUCTION}

To apply the ultrasound hyperthermia for the treatment of bone tumor, it is necessary to avoid overheating the bone marrow and bone behind the tumor. Owing to the high absorption of bone [1] and the uncertain absorption coefficient of the bone marrow, a limited low level of ultrasound intensity should be maintained to avoid high temperature on the bone marrow and bone [2].

This work used a relatively simple model [3] to estimate the ultrasound intensity or specific absorption ratio (SAR) distribution. The total ultrasound energy followed the exponential law for attenuation and uniform ideal power deposition within the cone-shape model. In this cone-shape model, the acoustic power is assumed to be equal in the same depth. The density ratio of bone to tumor, diameter of the acoustic window, tumor size, tumor depth, ultrasound attenuation in the bone tumor tissue, the absorption on the bone, and the driving frequency of transducer have been investigated to find the appropriate driving frequency for a

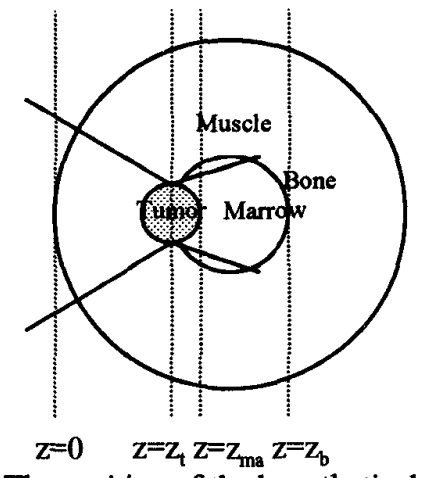

Fig. 1 The position of the hypothetical tumor

given tumor depth and tumor size, and to estimate the therapeutic domain for a given acoustic window on the skin surface of the limbs. The results are helpful to the treatment planning and the design of ultrasound hyperthermic transducer for bone tumors.

\section{METHODS}

In this cone-shape model, the acoustic power is assumed to be equal in the same depth [3]. Then, we have: $\mathrm{Q}(\mathrm{z})=\mathrm{Q}(0) \cdot \exp \left\{-2\left[\left(\sum \mu_{\mathrm{i}-1}\left(\mathrm{z}_{\mathrm{i}-1}-\mathrm{z}_{\mathrm{i}-2}\right)\right)+\mu_{\mathrm{i}}\left(\mathrm{z}-\mathrm{z}_{\mathrm{i}-1}\right)\right]\right\}$

$\mathrm{i}=1,2,3,4$ till $\mathrm{z}_{\mathrm{i}-1}<\mathrm{z}^{2}<\mathrm{z}_{\mathrm{i}}$

$\mu_{0}=0, \quad \mu_{1}=\mu_{\text {muscle, }}, \mu_{2}=\mu_{\text {tumor }}, \quad \mu_{3}=\mu_{\text {bone marrow, }}, \mu_{4}=\mu_{\text {bone }}$ $\mathrm{z}_{0}=0, \mathrm{z}_{1}=\mathrm{z}_{\text {muscle }}, \mathrm{z}_{2}=\mathrm{z}_{\text {bone marrow }}, \mathrm{z}_{3}=\mathrm{z}_{\text {bone }}$

$\mathrm{I}(\mathrm{z})=\mathrm{Q}(\mathrm{z}) / \alpha$

Here, $Q(0)$ denotes the total energy propagating through the acoustic window whose area is $\mathrm{A}(0)=\pi[\mathrm{d}(0) / 2]^{2} . \mathrm{Q}(\mathrm{z})$, in this model, is the total energy propagating through the depth z. Due to $100 \%$ transmission, this model overestimates the bone heating. The actual temperature in the bone would be lower than predicted by the model.

Assuming that the ultrasound intensities are not large enough to cause wave distortion, the attenuation and absorption coefficients of tissue are equal. All of the attenuated energy is absorbed in the heating field. Thus, the SAR in the homogeneous and uniformly attentive media is proportional to the ultrasound intensity. Hence, we can obtain the ratio of SAR at the tumor depth to that on the acoustic window area as:

$$
\mathrm{SR}(\mathrm{z}, 0)=\frac{\operatorname{SAR}(\mathrm{z})}{\operatorname{SAR}(0)}=\frac{\alpha(\mathrm{z}) \bullet \mathrm{I}(\mathrm{z}) / \rho(\mathrm{z})}{\alpha(0) \bullet \mathrm{I}(0) / \rho(0)}
$$




$$
\begin{aligned}
& =[\operatorname{AR}(\mathrm{z}, 0) / \mathrm{DR}(\mathrm{z}, 0)] \cdot \frac{\mathrm{I}(\mathrm{z})}{\mathrm{I}(0)}=[\operatorname{AR}(\mathrm{z}, 0) / \mathrm{DR}(\mathrm{z}, 0)] \cdot \frac{\mathrm{Q}(\mathrm{z}) / \mathrm{A}(\mathrm{z})}{\mathrm{Q}(0) / \mathrm{A}(0)} \\
& =\mathrm{GG} \cdot[\mathrm{AR}(\mathrm{z}, 0) / \mathrm{DR}(\mathrm{z}, 0)] \cdot \exp \left\{-2\left[\left(\sum \mu_{\mathrm{i}-1}\left(\mathrm{z}_{\mathrm{i}-\mathrm{l}}-\mathrm{z}_{\mathrm{i}-2}\right)\right)+\mu\right.\right. \\
& \left.\left.\mathrm{i}\left(\mathrm{z}-\mathrm{z}_{\mathrm{i}-1}\right)\right]\right\}
\end{aligned}
$$

Here, $\operatorname{SR}(z, 0)$ is the ratio of specific absorption rate (SAR) of ultrasound at the depth $z$ to that on the skin surface. I(0) denotes the ultrasound intensity of the acoustic window on the skin surface. I(z) is the ultrasound intensity in the depth of $z$. AR denotes the absorption ratio of the tissue in the depth $\mathrm{z}$ (it could be muscle, tumor, bone marrow or bone) to muscle (skin surface). GG, $A(0) / A(z)$, is the geometrical gain which can overcome the ultrasound attenuation to form the focal zone. $\operatorname{AR}(\mathrm{z}, 0)$ is the absorption ratio of the tissue in depth $\mathrm{z}$ to the skin surface. $\mathrm{DR}(\mathrm{z}, 0)$ is the density ratio of the tissue in depth $z$ to the skin surface. To deliver the ultrasound energy into the tumor site and to avoid the potential damage to the normal tissue as much as possible, the ratio values of SAR distributions have to meet the following 3 criteria [3]:

$$
\begin{aligned}
& \operatorname{SR}\left(z_{t}, 0\right) \geqq 3 \\
& \operatorname{SR}\left(z_{t}, z_{\text {ma }}\right) \geqq 3 \\
& \operatorname{SR}\left(z_{t}, z_{b}\right) \geqq 3
\end{aligned}
$$

Under these 3 criteria, the SAR in bone tumor site is three times higher than the SARs in surface skin, bone marrow and bone. Therefore, we can obtain a safe and efficient hyperthermic heating.

As the condition of Equ. (4.a), from Equ. (3) and the anatomic relationship shown in Fig. 1, we have:

$\mathrm{SR}\left(\mathrm{z}_{\mathrm{t}}, 0\right)=\left[\left(\mathrm{d}(0) / \mathrm{d}\left(\mathrm{z}_{\mathrm{t}}\right)\right]^{2} \cdot[\mathrm{AR}(\right.$ tumor, muscle $) / \mathrm{DR}($ tumor, muscle $)] \bullet \exp \left\{-2 \cdot\left[\mu_{\text {muscle }} \bullet\left(z_{t}-0.5 \cdot d\left(z_{i}\right)\right)+\mu_{\text {tumor }} \bullet(0.5\right.\right.$ - $\left.\left.\left.\mathrm{d}\left(\mathrm{z}_{\mathrm{f}}\right)\right)\right]\right\}$

Let $\mu_{\text {mussle }}$ equals to $\mu_{\text {umor }}$ to be the worst case of heating tumor and DR(tumor, muscle) $=1$. we have,

$\mathrm{d}\left(\mathrm{z}_{\mathrm{b}}\right)=\left(\mathrm{d}(0) /\left[\operatorname{SR}\left(\mathrm{z}_{\mathrm{b}} 0\right)\right]^{1 / 2}\right) \cdot \exp \left(\mu_{\text {muscle }} \cdot \mathrm{z}_{\mathrm{t}}\right)$

By considering the SR of tumor to bone marrow, we can derive,

$\mathrm{SR}\left(\mathrm{z}_{\mathrm{t}}, \mathrm{z}_{\mathrm{m}}\right)=\left[\mathrm{d}\left(\mathrm{z}_{\mathrm{ma}}\right) / \mathrm{d}\left(\mathrm{z}_{\mathrm{f}}\right)\right]^{2} \cdot[\mathrm{AR}($ tumor,bone marrow) $/ \mathrm{DR}$ (tumor,bone marrow) $] \bullet \exp \left[-2 \cdot \mu_{\text {tumor }} \bullet\left(z_{\mathrm{ma}}-\mathrm{z}_{\mathrm{f}}\right)\right]$

where,

$\mathrm{z}_{\mathrm{ma}}=\mathrm{z}_{\mathrm{t}}+0.5 \cdot \mathrm{d}\left(\mathrm{z}_{\mathrm{t}}\right)$

$\mathrm{d}\left(\mathrm{z}_{\mathrm{ma}}\right)=\mathrm{d}\left(\mathrm{z}_{\mathrm{f}}\right)+\left[\left(\mathrm{z}_{\mathrm{ma}}-\mathrm{z}_{\mathrm{f}}\right) / \mathrm{z}_{\mathrm{t}}\right] \cdot\left(\mathrm{d}(0)-\mathrm{d}\left(\mathrm{z}_{\mathrm{i}}\right)\right)$

Also, let $\mu_{\text {muscle }}$ equals to $\mu_{\text {tumor }}$ and $\mathrm{DR}$ (tumor, bone marrow) $=1$ then

$\left\{1+0.5 \cdot \mathrm{d}(0) / \mathrm{z}_{\mathrm{t}}-0.5 \cdot \mathrm{d}\left(\mathrm{z}_{\mathrm{t}}\right) / \mathrm{z}_{\mathrm{t}}\right\}^{2} \cdot \exp \left[\mu_{\text {muscle }}\right.$

$\operatorname{SR}\left(\mathrm{z}_{\mathrm{t}}, \mathrm{z}_{\mathrm{m})}\right) \cdot \mathrm{AR}$ (bone marrow, tumor)

$\left.d\left(z_{1}\right)\right]=$

By considering the SR of tumor to bone, we can derive, $\operatorname{SR}\left(\mathrm{z}_{\mathrm{b}}, \mathrm{z}_{\mathrm{b}}\right)=\left[\mathrm{d}\left(\mathrm{z}_{\mathrm{b}}\right) / \mathrm{d}\left(\mathrm{z}_{\mathrm{l}}\right]^{2} \cdot[\right.$ AR(tumor, bone $) / \mathrm{DR}($ tumor, bone) $] \cdot \exp \left[-2 \cdot \mu_{\text {tmor }} \bullet\left(\mathrm{z}_{\mathrm{ma}}-\mathrm{z}_{\mathrm{t}}\right)\right]$

where,

$$
\begin{aligned}
& z_{m a}=z_{t}+0.5 \cdot d\left(z_{b}\right) \\
& d\left(z_{b}\right)=d\left(z_{b}\right)+\left[\left(z_{b}-z_{b}\right) / z_{l}\right] \cdot\left(d(0)-d\left(z_{b}\right)\right)
\end{aligned}
$$

Also, let $\mu_{\text {muscle }}$ equals to $\mu_{\text {tumor }}$, the density of soft tissue is $1150 \mathrm{~kg} / \mathrm{cm}^{3}$ and the density of bone is $1500 \mathrm{~kg} / \mathrm{cm}^{3}$ [12], so DR(bone, tumor) $=1.39$. For the conservative consideration, we have $\mathrm{DR}$ (tumor, bone) $=1$, then

$\left\{1+\left[\left(z_{b}-z_{t}\right) / z_{t}\right] \cdot\left[\left(d(0) / d\left(z_{t}\right)\right)-1\right]\right\} \cdot \exp \left\{\mu_{\text {bone marow }} \bullet\left[z_{b}-\left(z_{t}\right.\right.\right.$ $\left.\left.\left.+\mathrm{d}\left(\mathrm{z}_{\mathrm{v}}\right) / 2\right)\right]+\mu_{\text {muscle }} \cdot\left(\mathrm{d}\left(\mathrm{z}_{\mathrm{v}}\right) / 2\right)\right\}=\left[\mathrm{SR}\left(\mathrm{z}_{\mathrm{t}}, \mathrm{z}_{\mathrm{b}}\right) \cdot \mathrm{AR}(\right.$ bone, tumor) $]^{1 / 2}$

Equation (6), (9) and (12) are used to evaluate the relationship between optimal attenuation and the therapeutic domain for given anatomic conditions and a given acoustic window on skin surface.

\section{RESULTS}

The results simulate a case of $z_{\mathrm{t}}=50 \mathrm{~mm}$ and $\mathrm{z}_{\mathrm{b}}=80 \mathrm{~mm}$ in Fig. 1. In this case, the diameter of acoustic window on skin surface, $d(0)$, is $100 \mathrm{~mm}$. $\operatorname{SR}\left(\mathrm{z}_{t}, 0\right) \geqq 3, \operatorname{SR}\left(\mathrm{z}_{t}, \mathrm{z}_{\mathrm{m} 2}\right) \geqq 3$, and $\operatorname{SR}\left(z_{v} z_{b}\right) \geqq 3$ to achieve a critical heating state.

To observe the DR(bone, tumor) effecting on the therapeutic tumor diameter, we have a range of DR(bone, tumor) from 1.0 to 1.5 shown in Fig. 2. Let $d(0)=100 \mathrm{~mm}$, $\mathrm{z}_{\mathrm{t}}=50 \mathrm{~mm}, \mathrm{z}_{\mathrm{b}}=80 \mathrm{~mm}(\mathrm{Db}=30 \mathrm{~mm}), \operatorname{SR}\left(\mathrm{z}_{\mathrm{t}}, 0\right) \geqq 3, \operatorname{SR}\left(\mathrm{z}_{\mathrm{t}}, \mathrm{z}_{\mathrm{ma}}\right)$ $\geqq 3, \operatorname{SR}\left(z_{t}, z_{b}\right) \geqq 3, \operatorname{AR}$ (muscle, tumor) $=1, \operatorname{AR}$ (bone marrow, tumor) $=1$, and $\operatorname{AR}($ bone, tumor) $=30$. The peaks are (26.36,15.37), (26.03,15.71), (25.21,16.26), (24.90,16.6), $(24.28,17.11)$ and $(23.86,17.41)$ of the curve $A$ to $F$ for the $\mathrm{DR}$ (bone, tumor) $=1.0,1.1,1.2,1.3,1.4$ and 1.5 , respectively. Therefore, the variation of DR(bone, tumor) results in a small change of therapeutic tumor diameter. For conservative consideration, we have $\mathrm{DR}$ (bone, tumor) $=1$ in Equ. (12). The DR(bone, tumor) $=1$ make a conservative physical meaning and a simplification of the equation.

Owing to the uncertain percentage of the bone trabeculi in bone marrow causing the uncertain attenuation coefficient of bone marrow, it is necessary to estimate the different absorption ratio of tumor to bone marrow. Let $\mathrm{d}(0)=100 \mathrm{~mm}, z_{\mathrm{r}}=50 \mathrm{~mm}, \mathrm{z}_{\mathrm{t}}=80 \mathrm{~mm}(\mathrm{Db}=30 \mathrm{~mm}), \mathrm{SR}\left(\mathrm{z}_{\mathrm{t}} 0\right)$ $\geqq 3, \operatorname{SR}\left(z_{t}, z_{m i n}\right) \geqq 3, \operatorname{SR}\left(z_{t}, z_{t}\right) \geqq 3$, AR(muscle, tumor) $=1$, and AR(bone, tumor) $=30$, we have investigated the effects of AR(bone marrow, tumor) to $\operatorname{Max}\left(\mathrm{d}\left(\mathrm{z}_{\mathrm{f}}\right)\right)$. The peaks in Fig. 3, as the display form of $\left(\mathrm{Mu}_{\mathrm{opt}} \operatorname{Max}\left(\mathrm{d}\left(\mathrm{z}_{\mathrm{f}}\right)\right)\right.$ ), are (31.03, $11.94),(26.36,15.47),(23.11,18.00)$, and $(0,0)$ for the $\mathrm{AR}$ (bone marrow, tumor) $=0.5,1.0,1.5$, and 2.0 , respectively. The curve $\mathrm{D}, \mathrm{d}\left(\mathrm{z}_{\mathrm{V}}\right)=0$, means that we can not find the frequency between 0 and $5 \mathrm{MHz}$ to meet the three criteria when the AR(bone marrow, tumor) $\geqq 2.0$. When $0.5 \leqq$ $\mathrm{AR}$ (bone marrow, tumor) $\leqq 1.5$, the $\mathrm{Mu}_{\text {opt }}$ decreases with the AR(bone marrow, bone), but the $\operatorname{Max}\left(\mathrm{d}\left(\mathrm{z}_{\mathrm{u}}\right)\right)$ increases with AR(bone marrow, tumor). The higher absorption of bone marrow causes less power deliver to bone, so the tumor 
to bone criterion is loosened to increase the treatable tumor diameter. The areas under the curve $A$ and $B$ meet the three criteria: $\operatorname{SR}\left(z_{b}, 0\right) \geqq 3, \operatorname{SR}\left(z_{b}, z_{m a}\right) \geqq 3$ and $\operatorname{SR}\left(z_{b}, z_{b}\right) \geqq 3$. In curve $C$, the attenuation of muscle $\leqq 18 \mathrm{~Np} / \mathrm{m}$ can not meet the criterion $\operatorname{SR}\left(z_{t}, z_{m 0}\right) \geqq 3$. When the attenuation $\geqq 19 \mathrm{~Np} / \mathrm{m}$, the area under curve $\mathrm{C}$ meet the three SR criteria.

If AR(bone marrow, tumor) $\geqq 2.0$, it can not meet $\operatorname{SR}\left(z_{4}, z_{\mathrm{ma}}\right) \geqq 3$ criterion. Let $\mathrm{d}(0)=100 \mathrm{~mm}, \mathrm{z}_{\mathrm{t}}=50 \mathrm{~mm}, \mathrm{z}_{\mathrm{b}}=80$ $\mathrm{mm}(\mathrm{Db}=30 \mathrm{~mm}), \mathrm{AR}$ (muscle, tumor) $=1$, and $\mathrm{AR}$ (bone, tumor) $=30$, to investigate the effects of AR(bone marrow, tumor) to $\operatorname{Max}\left(d\left(z_{i}\right)\right)$. Here, we skip the $\operatorname{SR}\left(z_{b}, z_{\mathrm{ma}}\right) \geqq 3$ criterion and obtain the results in Fig. 4. The peaks are (26.36,15.47), (20.99,20.11), (17.95,23.46), (16.12,25.97), and $(13.99,27.98)$ for the $\mathrm{AR}$ (bone marrow, tumor) $=1,2,3$, 4 , and 5 , respectively.

Let $d(0)=100 \mathrm{~mm}, \mathrm{Db}=30 \mathrm{~mm}, \mathrm{SR}\left(\mathrm{z}_{\mathrm{t}} 0\right) \geqq 3, \mathrm{SR}\left(\mathrm{z}_{\mathrm{t}}, \mathrm{z}_{\mathrm{ma}}\right)$ $\geqq 3, \operatorname{SR}\left(z_{t}, z_{b}\right) \geqq 3, A R$ (muscle, tumor)=AR(bone marrow, tumor) $=1$, and $A R$ (bone, tumor) $=30$, we have investigated the effects of tumor depth $\left(\mathrm{z}_{t}\right)$ to $\operatorname{Max}\left(\mathrm{d}\left(\mathrm{z}_{t}\right)\right)$ and $\mathrm{Mu}_{\mathrm{opt}}$. The relationship between the treatable tumor diameter $\left(\mathrm{d}\left(\mathrm{z}_{t}\right)\right.$ ) and the attenuation $(\mathrm{Mu})$ for the tumor located at different depth is depicted in Fig. 5. The peaks, as the display form of $\left(\mathbf{M u}_{\mathrm{opt}}\right.$ $\left.\operatorname{Max}\left(\mathrm{d}\left(\mathrm{z}_{t}\right)\right)\right)$, are $(27.27,18.94),(26.36,15.47),(24.93,12.70)$ and $(24.02,10.63)$ for the $z_{t}=40,50,60$ and 70 , respectively. The aforementioned curves demonstrate that the attenuation for those peaks, $\mathrm{Mu}_{\mathrm{opt}}$ and $\operatorname{Max}\left(\mathrm{d}\left(\mathrm{z}_{\mathrm{f}}\right)\right.$ ), decrease with the tumor depth $\left(\mathrm{z}_{t}\right)$. The areas under the curves $A$ to $E$ in Fig. 5 meet the three criteria. In curve F, the attenuation of muscle $\leqq 12 \mathrm{~Np} / \mathrm{m}$ can not meet the criterion $\operatorname{SR}\left(z_{t}, z_{m a}\right) \geqq 3$. When the attenuation $\geqq 12 \mathrm{~Np} / \mathrm{m}$, the area between F1 and F2 meet the three SR criteria.

Fig. 6 provides the simulation results revealing that the optimal attenuation is independent of the acoustic window on skin surface with $z_{t}=50 \mathrm{~mm}, D_{b}=30 \mathrm{~mm}, S R\left(z_{b} 0\right) \geqq$ $3, \operatorname{SR}\left(z_{t}, z_{m a}\right) \geqq 3, \operatorname{SR}\left(z_{t}, z_{t}\right) \geqq 3, \operatorname{AR}$ (muscle, tumor)=AR(bone marrow, tumor) $=1$, and $A R(b o n e$, tumor $)=30$. According to this figure the $\mathrm{Mu}_{\mathrm{opt}}$ is maintained at $26.36 \mathrm{~Np} / \mathrm{m}$ and the $\operatorname{Max}(d(0)) s$ are $0,0,11.41,15.47$ and $19.00 \mathrm{~mm}$ for the $d(0) s$ are $25,50,75,100$, and 125 .

Let $z_{t}=50, d(0)=100 \mathrm{~mm}, \quad S R\left(z_{t}, 0\right) \geqq 3, S R\left(z_{t}, z_{m a}\right) \geqq$ $3, \operatorname{SR}\left(z_{t}, z_{b}\right) \geqq 3, \operatorname{AR}$ (muscle, tumor) $=\operatorname{AR}$ (bone marrow, tumor) $=1$, and $A R$ (bone, tumor) $=30$, we have observed the effects of diameter of bone( $(\mathrm{Db})$ to $\operatorname{Max}\left(\mathrm{d}\left(\mathrm{z}_{\mathrm{t}}\right)\right.$ ) and $\mathrm{Mu}_{\mathrm{opt}}$. In Fig. 6, the $\mathrm{Mu}_{\text {opt }}$ decreases with the $\mathrm{Db}$, but $\operatorname{Max}\left(\mathrm{d}\left(\mathrm{z}_{\mathrm{t}}\right)\right.$ ) increases with the $\mathrm{Db}$. The peaks are $(50.0,4.04)$, $(35.32,9.65),(26.36,15.47)$, and $(20.90,20.38)$ for the $\mathrm{Db}=$ $10,20,30$, and $40 \mathrm{~mm}$. The larger $\mathrm{Db}$ causes more absorption in bone marrow to reduce power delivery to bone, so the criteria, $\operatorname{SR}\left(\mathrm{z}_{\mathrm{b}} \mathrm{z}_{\mathrm{b}}\right) \geq 3$, are loosened to increase the $d\left(z_{i}\right)$. The finding denotes that a lower driving frequency should use in a larger $\mathrm{Db}$; in addition, $\operatorname{Max}\left(\mathrm{d}\left(\mathrm{z}_{\mathrm{t}}\right)\right)$ become larger as the increasing $\mathrm{Db}$.

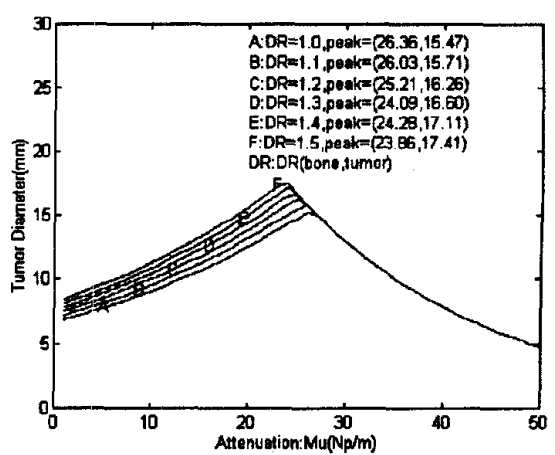

Fig. 2 DR(bone, tumor): the variation of DR(bone, tumor) results in a small change of therapeutic tumor diameter.

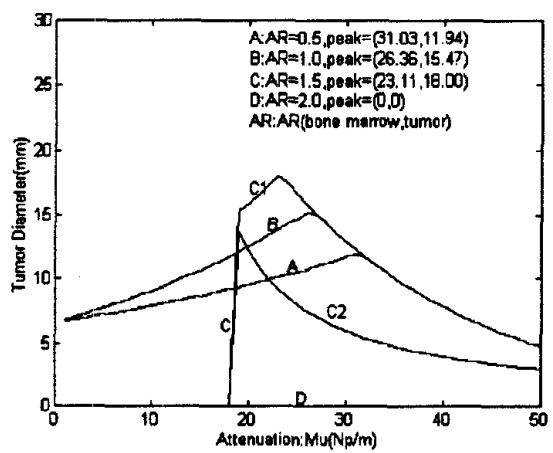

Fig. 3 AR(bone marrow, tumor) <2.0: the higher absorption of bone marrow causes less power deliver to bone, so the tumor to bone criterion is loosened to increase the therapeutic tumor diameter;

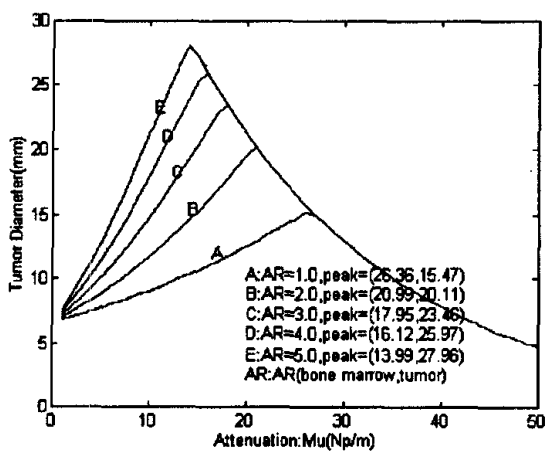

Fig. 4 AR(bone marrow, tumor) $\geqq 2.0$ : skipping the $\operatorname{SR}\left(\mathrm{z}_{b} \mathrm{z}_{\mathrm{ma}}\right)$ criterion, the higher absorption of bone marrow causes less power deliver to bone, so the tumor to bone criterion is loosened to increase the therapeutic tumor diameter;

\section{DISCUSSION}

The bone marrow is generally used to refer to the tissue occupying the cavities between the trabecular bone. Normal marrow is ether red, containing the haematopoietic elements, or yellow, composed mainly of fat cells. The 


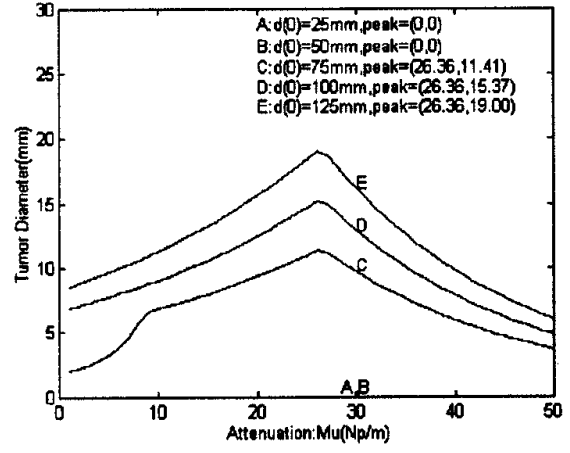

Fig. 5 curves demonstrate that the attenuation for those peaks, $\mathrm{Mu}_{\mathrm{opt}}$ and $\operatorname{Max}\left(\mathrm{d}\left(\mathrm{z}_{\mathrm{f}}\right)\right)$, decrease with the tumor depth.

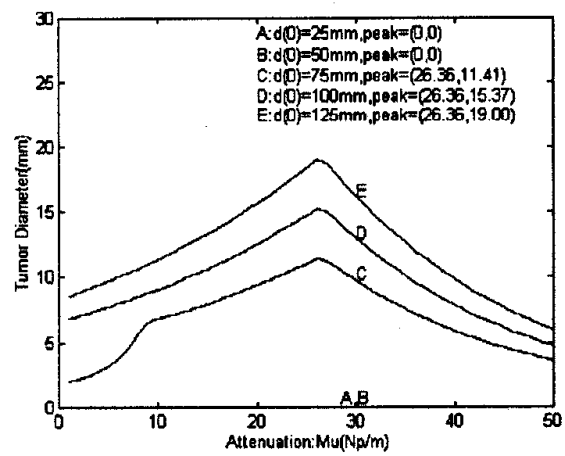

Fig. $6 \mathrm{~d}(0)$ : the $\mathrm{Mu}_{\mathrm{opt}}$ is independent of $\mathrm{d}(0)$.

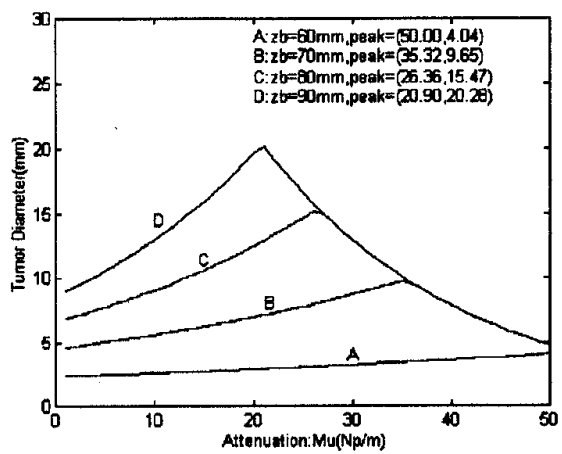

Fig. $7 \mathrm{z}_{\mathrm{b}}$ : the larger $\mathrm{Db}$ causes more absorption in bone marrow to reduce power delivery to bone, so the criteria, $\operatorname{SR}\left(z_{t}, z_{b}\right) \geqq 3$, are loosened to increase the $d\left(z_{t}\right)$.

marrow in diaphysis contains more fat and it in metaphysis contains more bone trabeculi. Therefore, we can assume that the ultrasound absorption of marrow in diaphysis is close to fat (AR(bone marrow, tumor) $=0.5$ ) and the marrow in metaphysis has a higher ultrasound absorption coefficient. A potential problem is that there is little experimental data available by the reports regarding the ultrasound absorption of bone marrow. For bovine trabecular bone, replacement of marrow by water led a reduction in the mean specific differential attenuation (SAD) of $2.0 \mathrm{dBcm}^{-1} \mathrm{MHz}^{-1}$ and 5.0 $\mathrm{dBcm}^{-1} \mathrm{MHz}^{-1}$ for the $500 \mathrm{kHz}$ and $1 \mathrm{MHz}$ transducer pairs, respectively [4]. We estimate $\mathrm{AR}$ (bone marrow, tumor) $=0.5$ to 5.0 in Fig. 3 and 4 that show the $\mathrm{Mu}_{\text {opt }}$ decreases with the AR(bone marrow, bone), the $\operatorname{Max}\left(d\left(z_{t}\right)\right)$ increases with AR(bone marrow, tumor). Therefore, the therapeutic diameter of tumor in metaphysis is greater than that in diaphysis. In another point of view, the diameter of the metaphysis is greater than diaphysis's in the long bone. As the Fig. 7 shown, the therapeutic diameter of bone tumor is increased with the diameter of bone. Thus, the therapeutic diameter of tumor in metaphysis is greater than that in diaphysis. According to these two results, we can find that the therapeutic diameter of tumor in the metaphysis is greater than that in diaphysis.

\section{CONCLUSION}

The bone tumor hyperthermia study described above applies a simplified ultrasound beam form model to examine the optimal driving frequency and treatable domain formed by the tumor size and tumor depth and to simulate the SAR distribution for the bone tumor hyperthermic treatment. The results demonstrate that the optimal driving frequency depends on the density ratio of bone to tumor, tumor depth, ultrasound absorption of bone marrow, and diameter of bone, however independent on the acoustic window area and SAR ratio under the conditions of three SR criteria. The results are helpful to fast estimate whether the bone tumor is treatable in the multilayer tissue condition, to choose the optimal operating frequency of ultrasound transducer and the acoustic window on the skin surface while the tumor size, tumor depth, diameter of bone are known, and to design ultrasound applicator for bone tumors.

\section{ACKNOWLEDGMENTS}

The authors thank the National Science Council and the Department of Health of the ROC for supporting this research NSC 85-2213-E-002-033 and DOH 85-HR-310.

$$
\text { REFERENCES }
$$

[1] J. F. Lehmann, B. J. deLateur, and C. G. Silverman, "Selective heating effects of ultrasound in human being," Arch. Phy. Med. Rehab., vol. 47, pp. 331-339, 1966.

[2] J. Tada, Y. Hayakawa and S. Kanoh, "Selective hyperthermia of bone by low frequency ultrasound wave I , II and III ," Proc. 5th Int. Sympo. Hyperthermic Oncology (Kyoto, Japan, 1988), vol. 1, pp. 908-914.

[3] W. L. Lin, J. Y. Yen, K. W. Jin, S. Y. Lin, and L.T. Lui, "Relationship between acoustic window and tumor conditions for external ultrasound hyperthermia," Proc. 7th Int. Cong. Hyperthermic Oncology (Roma, Italy, 1996), vol. 2, pp. 376-378

[4] J. M. Alves, J. T. Ryaby, J. J. Kaufman, F. P. Magee, and R. S. Siffert, "Influence of marrow on ultrasonic velocity and attenuation in bovine trabecular bone," Calcif. Tissue Int. vol. 58, pp. 362-367, 1996. 